\title{
Cobalt-promoted regioselective preparation of aryl tetrazole amines
}

\author{
KONDRAGANTI LAKSHMI ${ }^{\mathrm{a}}$, MANABOLU SURENDRA BABU ${ }^{\mathrm{b}, *}$ and \\ DITTAKAVI RAMACHANDRAN ${ }^{c}$ \\ a Jawaharlal Nehru Technological University Kakinada, Kakinada, Andhra Pradesh 533 003, India \\ ${ }^{\mathrm{b}}$ Department of Chemistry, Gitam School of Technology, Gitam University, HTP Campus, Rudraram, Medak, \\ Telangana 502 329, India \\ ${ }^{\mathrm{c}}$ Department of Chemistry, Acharya Nagarjuna University, Guntur, Andhra Pradesh 522 510, India \\ E-mail: manabolu@gmail.com
}

MS received 28 January 2018; revised 5 March 2018; accepted 17 March 2018; published online 17 April 2018

\begin{abstract}
A highly general, efficient and simple methodology for the regioselective synthesis of aryl tetrazole amines has been explored. The present method involves consecutive desulphurization and $C-N$ cross-coupling reaction. Cheap, readily available and air stable cobalt catalyst has been used for this methodology. In addition, the substrate scope has been demonstrated.
\end{abstract}

Keywords. Aryl tetrazole amines; regioselective synthesis; desulphurization; $C-N$ cross-coupling reaction; consecutive reaction.

\section{Introduction}

Very important heterocyclic class tetrazole is found in compounds (Figure 1) having anti-asthmatic, ${ }^{1}$ antiviral and anti-inflammatory ${ }^{2}$ and anti-neoplastic ${ }^{3}$ activities. In addition, tetrazoles are also used as ligands in coordination chemistry and they show medicinal applications. ${ }^{4}$ Therefore synthetic organic chemists have drawn immense attention for the preparation of substituted tetrazoles. In this connection, researchers have developed traditional methods for the construction of tetrazoles. Especially, addition of $\mathrm{NaNO}_{2}$ to amino-guanidine, ${ }^{5}$ addition of $\mathrm{NaN}_{3}$ to carbodiimides or cyanamides, ${ }^{6}$ reaction of amines with a leaving group in tetrazoles 5-position, ${ }^{7}$ nucleophilic substitution by $\mathrm{N}_{3}^{-}$ of (a) chlorine in $\alpha$-chloroformamidines ${ }^{8}$ and (b) sulfur from thioureas in presence of mercury ${ }^{9}$ or lead salts ${ }^{5 \mathrm{c}}$ or iodine. ${ }^{10} 5$-Substituted- $1 H$-tetrazoles are also prepared from the reaction between corresponding nitriles and $\mathrm{NaN}_{3}$ via [3+2] cycloaddition using $\mathrm{Zn}$ (II) salts ${ }^{11}$ and $\mathrm{ZnO}$ nanocrystal. ${ }^{12}$ Later, substituted tetrazoles have been prepared from the reaction between substituted

\footnotetext{
*For correspondence
}

nitriles and $\mathrm{TMSN}_{3}$ using $\mathrm{TBAF}^{13}$ and Copper catalyst. ${ }^{14}$ Often these methods use either toxic reagents or harsh reaction conditions such as high temperature, toxic reagents, unavailable starting precursors and lack of regioselectivity. ${ }^{15}$ To overcome the above-mentioned drawbacks we wish to develop a methodology for the synthesis of substituted tetrazoles from thiourea using cobalt via desulphurization/substitution/electro cyclization/ $C-N$ cross-coupling reaction. To the best of our knowledge, no report is available for the synthesis of tetrazoles from thiourea using cobalt.

\section{Experimental}

\subsection{General information}

$\mathrm{CS}_{2}, \mathrm{CoCl}_{2} \cdot 6 \mathrm{H}_{2} \mathrm{O}, \mathrm{CoSO}_{4} \cdot \mathrm{H}_{2} \mathrm{O}, \mathrm{Co}\left(\mathrm{NO}_{3}\right)_{2} \cdot 6 \mathrm{H}_{2} \mathrm{O}, \mathrm{Et}_{3} \mathrm{~N}$, Pyridine, sodium bicarbonate and ammonia were purchased from Aldrich and used without further purification. The solvents were purchased and dried according to standard procedure prior to use. ${ }^{11} \mathrm{H} \mathrm{NMR}(400 \mathrm{MHz})$ spectra were recorded with a Varian 400 spectrometer. Infrared (IR) spectra were recorded on a Perkin Elmer Spectrum one FT-IR spectrometer. Elemental analyses were recorded with Perkin Elmer CHNS analyzer. VKSI Medico Centrifuge was used 


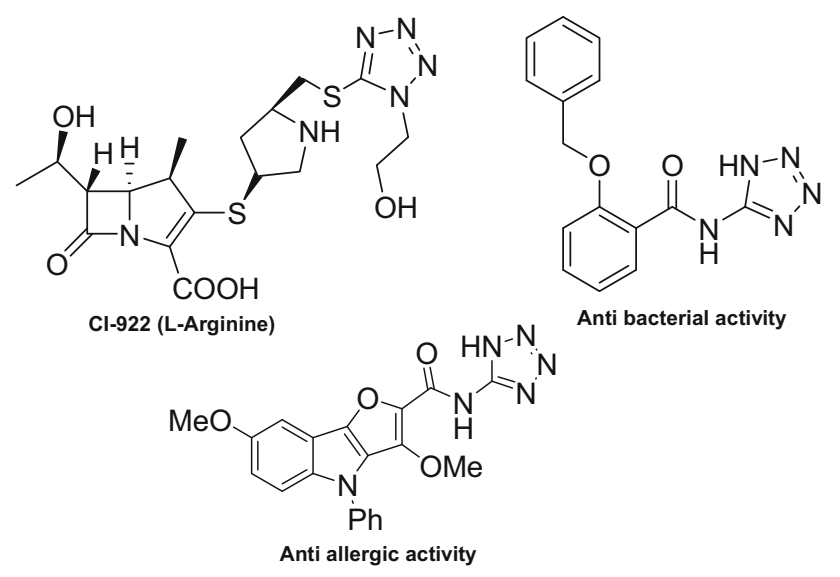

Figure 1. Some of the biological important aminotetrazoles.

for our experimental procedure for the synthesis of resulting compounds.

\subsection{Representative experimental procedure for the synthesis of Phenyl tetrazole amine (1a)}

To a stirred solution of DMSO $(2-3 \mathrm{~mL})$, thiourea ( $1 \mathrm{mmol}, 76$ $\mathrm{mg}$ ) was added in slowly and followed by $\mathrm{Et}_{3} \mathrm{~N}(1 \mathrm{mmol}, 101$ $\mathrm{mg})$ and $\mathrm{CoCl}_{2} \cdot 6 \mathrm{H}_{2} \mathrm{O}(50 \mathrm{~mol} \%, 119 \mathrm{mg})$ at room temperature. The whole reaction mixture stirred for one hour (until black colour) at room temperature. The reaction was monitored by TLC. After completion of the reaction (monitored by TLC), add $\mathrm{NaN}_{3}(2 \mathrm{mmol}, 130 \mathrm{mg}$ ) and the reaction mixture stirred for $1 \mathrm{~h}$. Later, iodobenzene ( $1 \mathrm{mmol}, 204 \mathrm{mg}), \mathrm{Cs}_{2} \mathrm{CO}_{3}$ $(1 \mathrm{mmol}, 325 \mathrm{mg}), \mathrm{CoCl}_{2} \cdot \mathrm{H}_{2} \mathrm{O}(10 \mathrm{~mol} \%, 23.8 \mathrm{mg})$ and $1,10-$ phenanthroline ( $20 \mathrm{~mol} \%, 36 \mathrm{mg}$ ) were added consecutively for several min and the reaction mixture was stirred for $18 \mathrm{~h}$ at $85^{\circ} \mathrm{C}$. The progress of the reaction was investigated by TLC ( $5 \%$ ethylacetate in hexane). After completion of the reaction, the reaction mixture was transferred into centrifuge tubes and centrifuged for $10 \mathrm{~min}$. Black solid settled at the bottom of centrifuge tubes. The clear solution was concentrated using rotary evaporator and the crude mixture was purified by silica gel (60-120 mesh) column chromatography using 30\% ethylacetate in hexane as eluent to obtain a phenyl tetrazole amine $\mathbf{1 a}$ as a white solid.

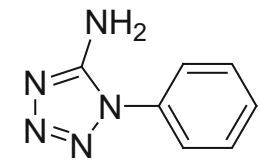

1-Phenyl-1H-tetrazol-5-amine (1a): Analytical TLC on silica gel, 3:7 ethyl acetate/hexane $\left(\mathrm{R}_{\mathrm{f}}\right.$ 0.6). Yield $296 \mathrm{mg}(92 \%)$, White solid, M.p. $167-168^{\circ} \mathrm{C}$ ( $\mathrm{Lit}^{33}$ M.p. $162-163^{\circ} \mathrm{C}$ ). ${ }^{1} \mathrm{H}$ NMR (400 MHz, $\left.\mathrm{CDCl}_{3}\right), \delta$, ppm: $7.97\left(2 \mathrm{H}\right.$, br. s, $\left.\mathrm{NH}_{2}\right)$; 7.61-7.57 (m, 2H, H Ar); 7.40-7.28 (m, 2H, H Ar); 7.217.17 (m, $1 \mathrm{H}, \mathrm{H} \mathrm{Ar}) .{ }^{13} \mathrm{C}$ NMR $\left(100 \mathrm{MHz}, \mathrm{CDCl}_{3}\right), \delta$, ppm: $137.8 ; 130.9 ; 130.6 ; 130.1 ; 128.9$. FT-IR $(\mathrm{KBr}) \mathrm{cm}^{-1}$ : 3987; 3350; 3064; 1693; 1587; 1250; 1148; 1070; 909; 764. Anal. Calcd. for $\mathrm{C}_{7} \mathrm{H}_{7} \mathrm{~N}_{5}$ : C, 52.17; H, 4.38; N, 43.45. Found: C, 52.30; H, 4.34; N, 43.36.

\subsection{General procedure for the synthesis of diphenyl tetrazole amine (1)}

To a stirred solution of DMSO (2-3 mL), thiourea (1 mmol, $76 \mathrm{mg}$ ) was added slowly, followed by $\mathrm{Et}_{3} \mathrm{~N}$ (1 mmol, 101 $\mathrm{mg})$ and $\mathrm{CoCl}_{2} \cdot 6 \mathrm{H}_{2} \mathrm{O}(50 \mathrm{~mol} \%, 119 \mathrm{mg})$ was added at room temperature. The whole reaction mixture stirred for one hour (until getting the black colour) at room temperature. The reaction was monitored by TLC. After completion of the reaction (monitored by TLC), to this, $\mathrm{NaN}_{3}(2 \mathrm{mmol}, 130 \mathrm{mg}$ ) was added. Then, the reaction mixture stirred for $1 \mathrm{~h}$. Later, iodobenzene ( $2 \mathrm{mmol}, 408 \mathrm{mg}), \mathrm{Cs}_{2} \mathrm{CO}_{3}(1.5 \mathrm{mmol}, 485 \mathrm{mg}$ ), $\mathrm{CoCl}_{2} \cdot \mathrm{H}_{2} \mathrm{O}(10 \mathrm{~mol} \%, 23.8 \mathrm{mg})$ and 1,10-phenanthroline (20 mol\%, $36 \mathrm{mg}$ ) were added consecutively for several min and the reaction mixture was stirred for $24 \mathrm{~h}$ at $115^{\circ} \mathrm{C}$. The progress of the reaction was investigated by TLC ( $5 \%$ ethylacetate in hexane). After completion of the reaction, the reaction mixture was transferred into centrifuged tubes and the mixture was centrifuged for $10 \mathrm{~min}$ by using centrifugation machine. Black colour solid settled at the bottom of centrifuged tubes. The clear solution was concentrated by using rotary evaporator and the crude mixture was purified by silica gel (60-120 mesh) column chromatography using $30 \%$ ethylacetate in hexane as eluent to obtain a phenyl tetrazole amine $\mathbf{1 b}$ as a white solid.<smiles>c1ccc(Nc2nnnn2-c2ccccc2)cc1</smiles>

$N, 1$-Diphenyl-1 $H$-tetrazol-5-amine1b: Analytical TLC on silica gel, 3:7 ethyl acetate/hexane $\left(\mathrm{R}_{\mathrm{f}}, 0.7\right)$; yield 95\%; ${ }^{1} \mathrm{H} \mathrm{NMR}\left(400 \mathrm{MHz}, \mathrm{CDCl}_{3}\right) \delta 7.54-7.41(\mathrm{~m}, 7 \mathrm{H}), 6.85(\mathrm{~d}$, $J=8.8 \mathrm{~Hz}, 3 \mathrm{H}), 6.02($ br s, $1 \mathrm{NH}) ;{ }^{13} \mathrm{C}$ NMR $(100 \mathrm{MHz}$, $\left.\mathrm{CDCl}_{3}\right) \delta 138.4,132.8,131.6,129.2,128.5,128.1,121.5$, 120.9, 117.6; FT-IR (KBr) 3426, 3097, 1645, 1631, 1567, 1512, 1491, 1287, 1250, 1146, 1027, $896 \mathrm{~cm}^{-1}$. Anal. Calcd. for $\mathrm{C}_{13} \mathrm{H}_{11} \mathrm{~N}_{5}$ : C, 65.81; H, 4.67; N, 29.52. Found: C, 65.90; $\mathrm{H}, 4.65 ; \mathrm{N}, 29.45$.

\section{Results and Discussion}

As shown below Scheme 1, thiourea gave amino tetrazole $\mathbf{A}$ as intermediate via desulphurization followed by cycloaddition. The intermediate $\mathbf{A}$ gave $C-N$ crosscoupled product with aryl iodide under mild reaction conditions.

Initially, the optimization reaction condition was performed using readily available thiourea as a model substrate with various solvents, bases, ligands and cobalt sources. We were glad to observe that the reaction could give target product 1a in complete conversion 

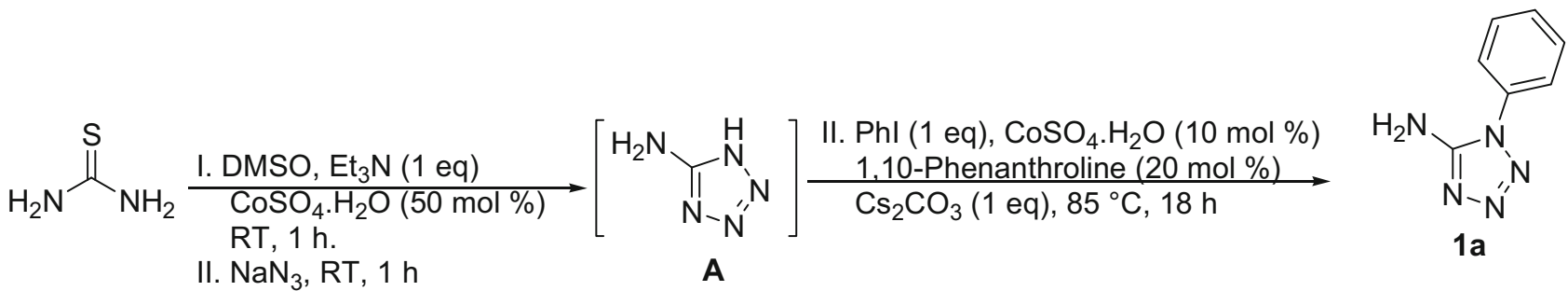

Scheme 1. Pathway for the synthesis of phenyltetrazoleamine.

Table 1. Optimization for the synthesis of phenyltetrazoleamine ${ }^{\mathrm{a}}$.

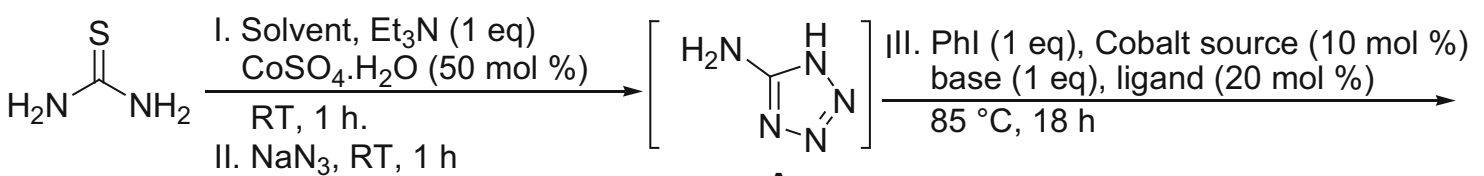

A<smiles>NCCN</smiles>

L1<smiles>OCCO</smiles>

L2<smiles>c1cnc2c(c1)ccc1cccnc12</smiles>

L3<smiles>Nc1nnnn1-c1ccccc1</smiles>

$1 \mathrm{a}$<smiles>c1ccc(Nc2nnnn2-c2ccccc2)cc1</smiles>

$1 \mathrm{~b}$

\begin{tabular}{|c|c|c|c|c|c|c|c|}
\hline \multirow[t]{2}{*}{ Entry } & \multirow[t]{2}{*}{ Solvent } & \multirow[t]{2}{*}{ Cobalt source } & \multirow[t]{2}{*}{ Base } & \multirow[t]{2}{*}{ Ligand } & \multicolumn{3}{|c|}{ Conversion $(\%)^{\mathrm{b}}$} \\
\hline & & & & & $\mathrm{A}$ & $1 \mathrm{a}$ & $1 b$ \\
\hline 1 & $\mathrm{EtOH}$ & $\mathrm{CoCl}_{2} \cdot 6 \mathrm{H}_{2} \mathrm{O}$ & $\mathrm{K}_{3} \mathrm{PO}_{4} \cdot 3 \mathrm{H}_{2} \mathrm{O}$ & L3 & 100 & n.d. & n.d. \\
\hline 2 & EtOAc & $\mathrm{CoCl}_{2} \cdot 6 \mathrm{H}_{2} \mathrm{O}$ & $\mathrm{K}_{3} \mathrm{PO}_{4} \cdot 3 \mathrm{H}_{2} \mathrm{O}$ & L3 & 100 & n.d. & n.d. \\
\hline 3 & DMF & $\mathrm{CoCl}_{2} \cdot 6 \mathrm{H}_{2} \mathrm{O}$ & $\mathrm{K}_{3} \mathrm{PO}_{4} \cdot 3 \mathrm{H}_{2} \mathrm{O}$ & L3 & 35 & 65 & n.d. \\
\hline 4 & DMSO & $\mathrm{CoCl}_{2} \cdot 6 \mathrm{H}_{2} \mathrm{O}$ & $\mathrm{K}_{3} \mathrm{PO}_{4} \cdot 3 \mathrm{H}_{2} \mathrm{O}$ & L3 & 30 & 70 & n.d. \\
\hline 5 & DMSO & $\mathrm{CoCl}_{2} \cdot 6 \mathrm{H}_{2} \mathrm{O}$ & $\mathrm{KOH}$ & L3 & 20 & 80 & n.d. \\
\hline 6 & DMSO & $\mathrm{CoCl}_{2} \cdot 6 \mathrm{H}_{2} \mathrm{O}$ & $\mathrm{K}_{2} \mathrm{CO}_{3}$ & L3 & 45 & 55 & n.d. \\
\hline 7 & DMSO & $\mathrm{CoCl}_{2} \cdot 6 \mathrm{H}_{2} \mathrm{O}$ & $\mathrm{Cs}_{2} \mathrm{CO}_{3}$ & L3 & n.d. & 100 & n.d. \\
\hline 8 & DMSO & $\mathrm{CoCl}_{2} \cdot 6 \mathrm{H}_{2} \mathrm{O}$ & $\mathrm{Cs}_{2} \mathrm{CO}_{3}$ & L1 & 80 & 20 & n.d. \\
\hline 9 & DMSO & $\mathrm{CoCl}_{2} \cdot 6 \mathrm{H}_{2} \mathrm{O}$ & $\mathrm{Cs}_{2} \mathrm{CO}_{3}$ & L2 & 60 & 40 & n.d. \\
\hline 10 & DMSO & $\mathrm{CoSO}_{4} \cdot \mathrm{H}_{2} \mathrm{O}$ & $\mathrm{Cs}_{2} \mathrm{CO}_{3}$ & L3 & n.d. & 100 & n.d. \\
\hline 11 & DMSO & $\mathrm{Co}\left(\mathrm{NO}_{3}\right)_{2} \cdot 6 \mathrm{H}_{2} \mathrm{O}$ & $\mathrm{Cs}_{2} \mathrm{CO}_{3}$ & L3 & n.d. & 100 & n.d. \\
\hline $12^{\mathrm{c}}$ & DMSO & $\mathrm{CoSO}_{4} \cdot \mathrm{H}_{2} \mathrm{O}$ & $\mathrm{Cs}_{2} \mathrm{CO}_{3}$ & L3 & 45 & 55 & n.d. \\
\hline $13^{\mathrm{d}}$ & DMSO & $\mathrm{CoSO}_{4} \cdot \mathrm{H}_{2} \mathrm{O}$ & $\mathrm{Cs}_{2} \mathrm{CO}_{3}$ & L3 & 50 & 50 & n.d. \\
\hline 14 & DMSO & $\mathrm{CoSO}_{4} \cdot \mathrm{H}_{2} \mathrm{O}$ & $\mathrm{Cs}_{2} \mathrm{CO}_{3}$ & - & 80 & 20 & n.d. \\
\hline 15 & DMSO & - & $\mathrm{Cs}_{2} \mathrm{CO}_{3}$ & - & 100 & n.d. & n.d. \\
\hline $16^{\mathrm{e}}$ & DMSO & $\mathrm{CoSO}_{4} \cdot \mathrm{H}_{2} \mathrm{O}$ & $\mathrm{Cs}_{2} \mathrm{CO}_{3}$ & L3 & n.d. & 100 & n.d. \\
\hline $17^{\mathrm{f}}$ & DMSO & $\mathrm{CoSO}_{4} \cdot \mathrm{H}_{2} \mathrm{O}$ & $\mathrm{Cs}_{2} \mathrm{CO}_{3}$ & L3 & n.d. & 85 & 15 \\
\hline $18^{\mathrm{g}}$ & DMSO & $\mathrm{CoSO}_{4} \cdot \mathrm{H}_{2} \mathrm{O}$ & $\mathrm{Cs}_{2} \mathrm{CO}_{3}$ & L3 & n.d. & 50 & 50 \\
\hline $19^{\mathrm{h}}$ & DMSO & $\mathrm{CoSO}_{4} \cdot \mathrm{H}_{2} \mathrm{O}$ & $\mathrm{Cs}_{2} \mathrm{CO}_{3}$ & L3 & n.d. & n.d & 100 \\
\hline
\end{tabular}

a Reaction conditions: Thiourea $(1 \mathrm{mmol})$, solvent $(2 \mathrm{~mL}), \mathrm{Et}_{3} \mathrm{~N}(1 \mathrm{eq}), \mathrm{CoSO}_{4} \cdot \mathrm{H}_{2} \mathrm{O}(50 \mathrm{~mol} \%), 1 \mathrm{~h}$, room temperature, then, $\mathrm{NaN}_{3}(2 \mathrm{mmol})$, room temperature, then, iodo benzene (1 mmol), catalyst (10 mol\%), ligand (20 mol\%), base (1 mmol), $18 \mathrm{~h}$, $85^{\circ} \mathrm{C}$. ${ }^{\mathrm{b}}$ Conversion was confirmed crude $1 \mathrm{H}$ NMR. ${ }^{\mathrm{c}}$ Cobalt source $(5 \mathrm{~mol} \%)$ used. ${ }^{\mathrm{d}} \mathrm{Cs}_{2} \mathrm{CO}_{3}$ (0.5 equiv) used. ${ }^{\mathrm{e}}$ Iodobenzene (2 eq) was used. ${ }^{\mathrm{f}}$ Iodobenzene ( $\left.2 \mathrm{eq}\right)$ and temp $100^{\circ} \mathrm{C}$ were used. ${ }^{\mathrm{g}}$ Iodobenzene $(2 \mathrm{eq})$, temp. $100^{\circ} \mathrm{C}$ and $\mathrm{Cs}_{2} \mathrm{CO}_{3}(1.5 \mathrm{eq})$ were used. ${ }^{\mathrm{h}}$ Iodobenzene ( $\left.2 \mathrm{eq}\right)$, temp $115^{\circ} \mathrm{C}$ and $\mathrm{Cs}_{2} \mathrm{CO}_{3}(1.5 \mathrm{eq})$ were used (n.d. for not detected). 
Table 2. Substrate scope for the synthesis of substituted aryltetrazoleamines ${ }^{\mathrm{a}}$.

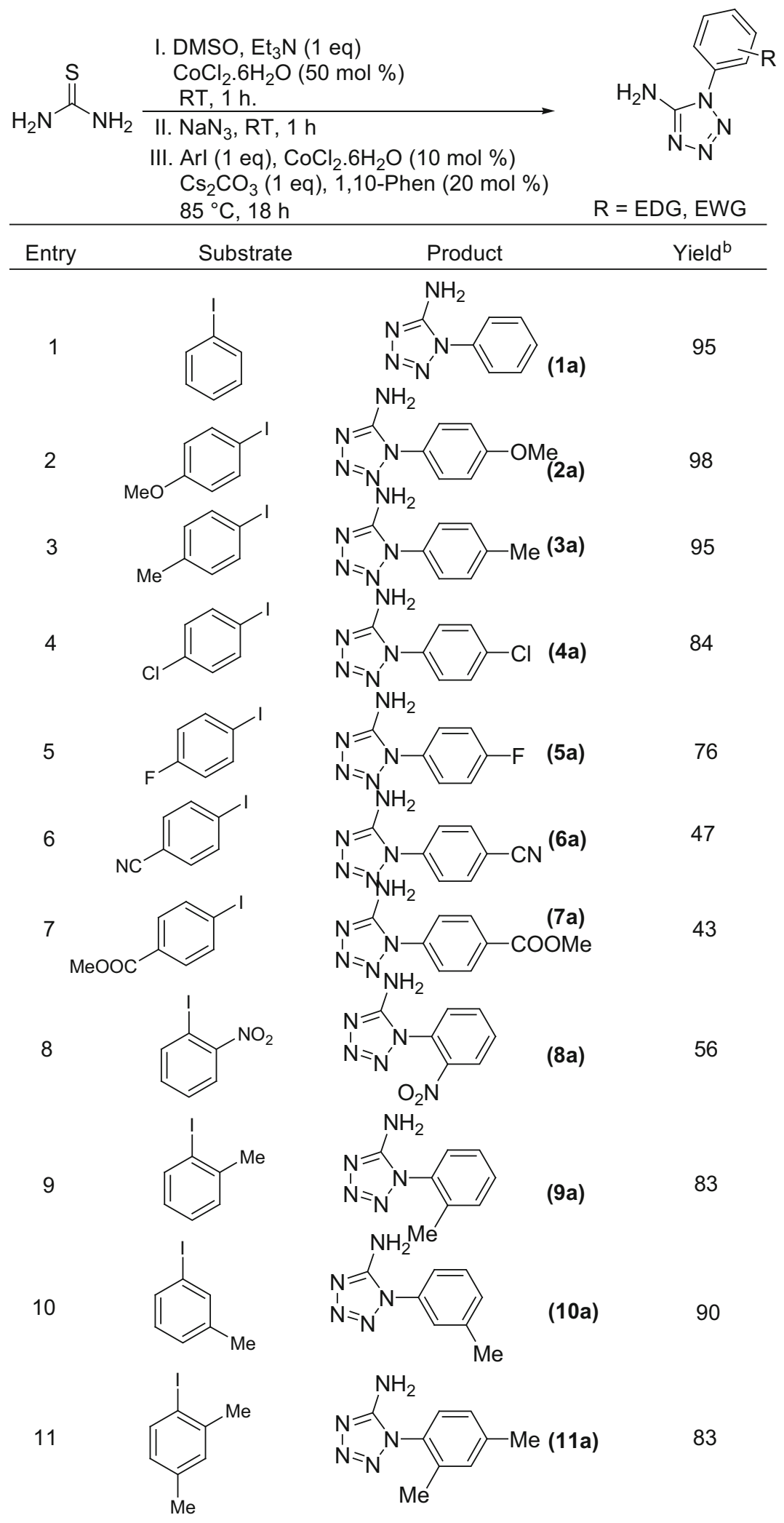

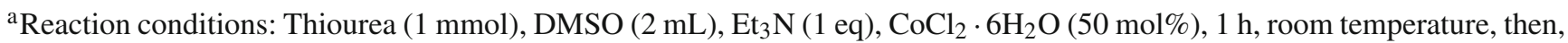
then, $\mathrm{NaN}_{3}(2 \mathrm{mmol})$, room temperature, $1 \mathrm{~h}$, then, $\mathrm{CoCl}_{2} \cdot 6 \mathrm{H}_{2} \mathrm{O}(10 \mathrm{~mol} \%)$, ArI $(1 \mathrm{mmol})$, ligand $(20 \mathrm{~mol} \%), \mathrm{Cs}_{2} \mathrm{CO}_{3}(1$ $\mathrm{mmol}), 18 \mathrm{~h}, 85^{\circ} \mathrm{C}$. ${ }^{b}$ Isolated yield. 
Table 3. Substrate scope for the synthesis of substituted diaryltetrazoleamines ${ }^{\mathrm{a}}$.

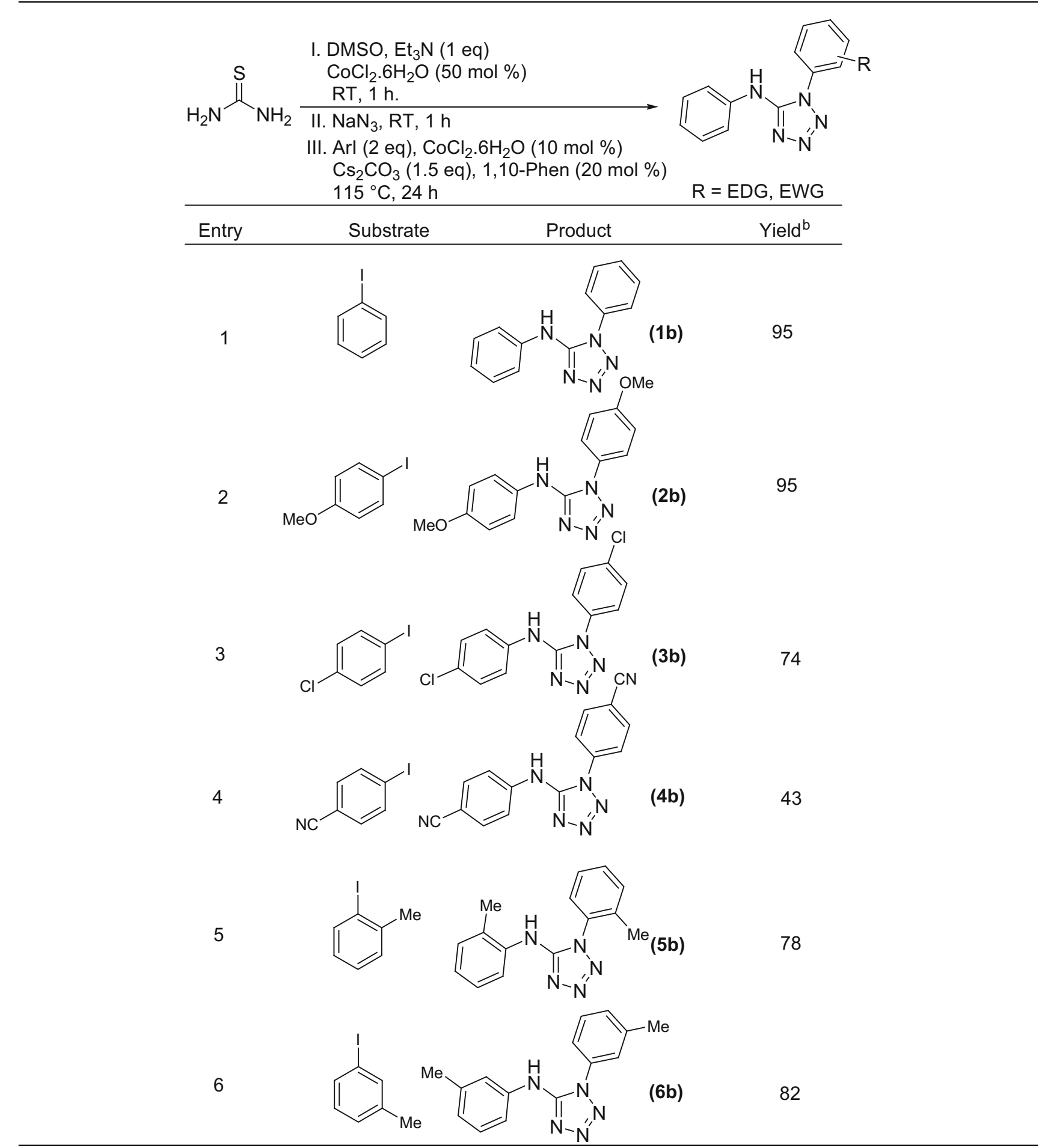

${ }^{a}$ Reaction conditions: Thiourea ( $\left.1 \mathrm{mmol}\right), \mathrm{DMSO}(2 \mathrm{~mL}), \mathrm{Et}_{3} \mathrm{~N}(1 \mathrm{eq}), \mathrm{CoCl}_{2} \cdot 6 \mathrm{H}_{2} \mathrm{O}(50 \mathrm{~mol} \%), 1 \mathrm{~h}$, room temperature, then $\mathrm{NaN}_{3}(2 \mathrm{mmol}, 130 \mathrm{mg})$, room temperature, $1 \mathrm{~h}$, then Aryl iodide $(2 \mathrm{mmol}), \mathrm{CoCl}_{2} \cdot 6 \mathrm{H}_{2} \mathrm{O}(10 \mathrm{~mol} \%)$, ligand $(20 \mathrm{~mol} \%)$, $\mathrm{Cs}_{2} \mathrm{CO}_{3}(1.5 \mathrm{mmol}), 24 \mathrm{~h}, 115^{\circ} \mathrm{C} .{ }^{b}$ Isolated yield.

using $10 \mathrm{~mol} \%$ cobalt source, $20 \mathrm{~mol} \%$ Ligand $(1,10-$ Phenanthroline) and 1 equiv. $\mathrm{Cs}_{2} \mathrm{CO}_{3}$ at $85^{\circ} \mathrm{C}$ (Table 1 , entries $7 \&$ 10-11). In case of solvent optimization, DMSO was effective to provide the target product $1 \mathbf{1 a}$.
Other solvents such as EtOH and EtOAc could obtain amino tetrazole A in complete conversion, but it didn't give target product $\mathbf{1 a}$ (Table 1, entries 1,2). The reaction using $\mathrm{Cs}_{2} \mathrm{CO}_{3}$ exhibited greater reactivity compared to 


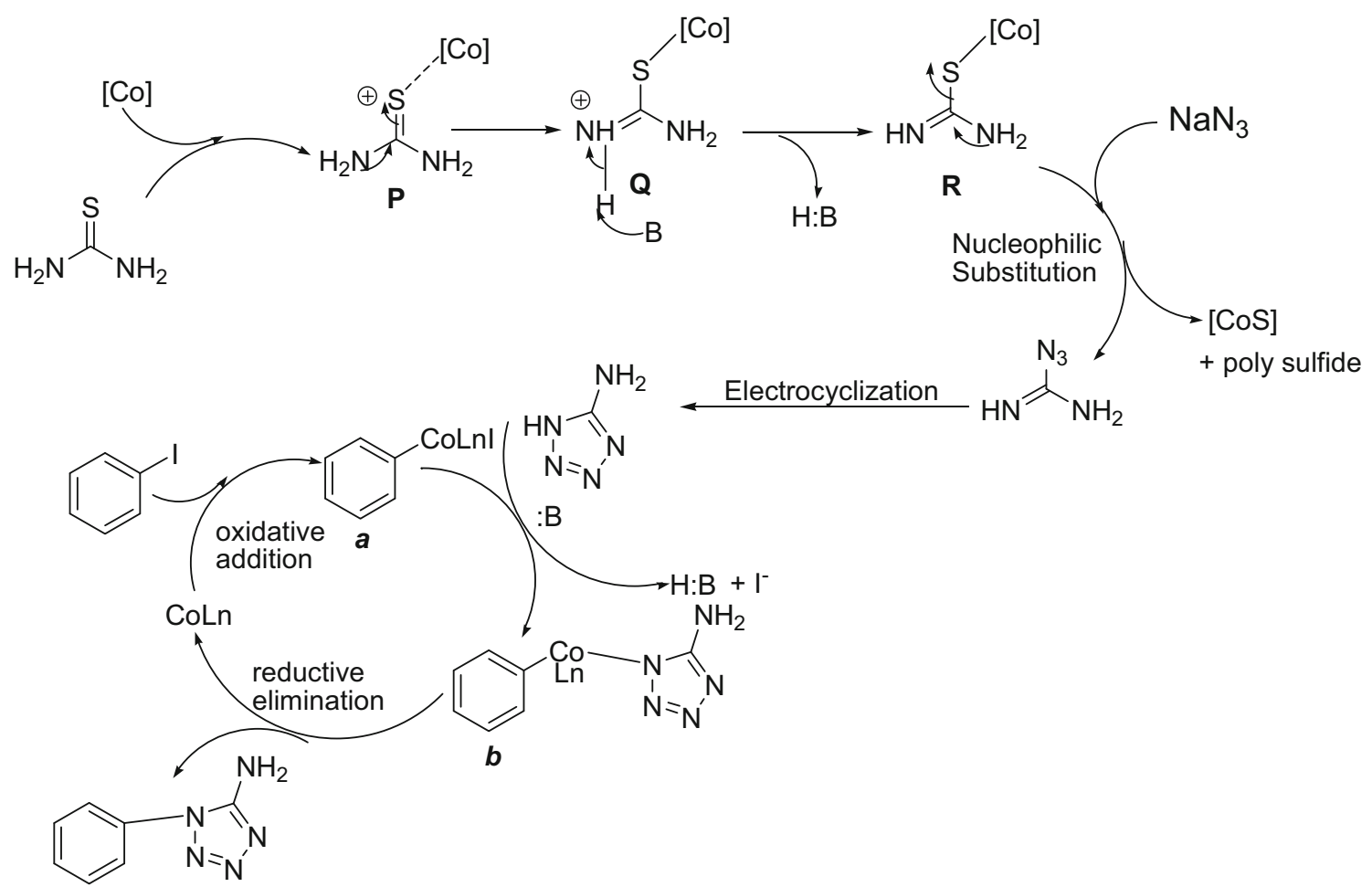

Scheme 2. Proposed mechanism.

that of $\mathrm{K}_{3} \mathrm{PO}_{4} \cdot 3 \mathrm{H}_{2} \mathrm{O}, \mathrm{K}_{2} \mathrm{CO}_{3}$ and $\mathrm{KOH}$. In a set of ligands $\mathbf{L 1}-\mathbf{L} 3$ screened, $\mathbf{L 3}$ (Table 1, entry 7) was found to be the most effective in comparison to $\mathbf{L 1}, \mathbf{L 2}$ (Table 1, entries 8-9). Cobalt sources $\left(\mathrm{CoCl}_{2} \cdot 6 \mathrm{H}_{2} \mathrm{O}, \mathrm{CoSO}_{4} \cdot \mathrm{H}_{2} \mathrm{O}\right.$ and $\left.\mathrm{Co}\left(\mathrm{NO}_{3}\right)_{2} \cdot 6 \mathrm{H}_{2} \mathrm{O}\right)$ exhibited a similar catalytic activity (Table 1, entries $7 \& 10,11$ ). Lowering the amount of base (1 equiv) or the cobalt source $(5 \mathrm{~mol} \%)$ led to the $N$-arylation to afford target product in less conversion (Table 1, entries 12-13). Control experiments without ligand (Table 1, entry 14) and the cobalt source (Table 1, entry 15) confirmed that the formation of final product was not observed. Very interestingly, the above reaction condition couldn't give diphenyltetrazolamine 1b. Therefore, we have focused for the synthesis of diphenyltetrazolamine from thiourea. In this connection, the standardization was done and the reaction could give product $\mathbf{1 b}$ in complete conversion using iodobenzene ( $2 \mathrm{eq}), \mathrm{Cs}_{2} \mathrm{CO}_{3}(1.5 \mathrm{eq})$ at $115^{\circ} \mathrm{C}$ (Table 1, entry 19).

Having the optimal conditions studied, the scope of the protocol was next explored to substituted phenyltetrazoleamines (Table 2). The substrates having both electron donating and electron withdrawing groups on the aryl rings could give their respective target products 1a-11a in moderate to high yield. Aryl iodide having electron donating substituents (4-Me, 2-Me, 4-OMe and 2, 4-diMe) showed greater reactivity compared to that of bearing electron withdrawing substituents (4-Cl, 4-F,
4-CN and 4-COOMe groups). The phenyl ring having electron donating groups such as 4-methyl, 4-methoxy could give their respective aromatic cyanamides $\mathbf{2 a}$, 3a in $95-98 \%$ yield. The unsubstituted phenyl ring also gave target product 1a in excellent yield. Electron withdrawing groups such as 4-fluoro and 4-chloro substituents provided their target products $\mathbf{4 a}$ and $\mathbf{5 a}$ in $76 \%$ and $84 \%$ yields, respectively. Aryl ring bearing other strong electron withdrawing substituents like nitrile, ester and nitro could give target products $6 \mathbf{a}-$ 8a in moderate yield. Aryl iodides bearing ortho and meta-substituted methyl groups readily underwent the reaction to give final products 9a, 10a in 83-90\% yields. Di-Methyl substituent on aryl ring gave target product in $83 \%$ yield. In addition, we explored the construction of diaryltetrazolamine under optimized reaction conditions (Table 3 ). Aryl iodides containing both electron donating and electron withdrawing groups as well as disubstituted groups readily underwent the reaction to provide target products $\mathbf{1 b}-\mathbf{6 b}$ in $43-95 \%$ yields.

The mechanism for the formation of substituted tetrazoles from thiourea is shown in below Scheme 2. We propose the mechanism from the experimental evidence and literature reports. ${ }^{18 \mathrm{~d}-\mathrm{i}}$ Cobalt can co-ordinate with thiourea, followed by removal of protons to afford intermediate $\mathbf{R}$ via intermediates $\mathbf{P}$ and $\mathbf{Q}$. The intermediate $\mathbf{R}$ may provide unsubstituted tetrazoles along with 


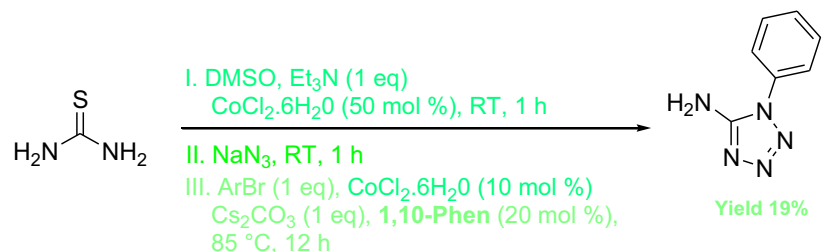

Scheme 3. Reaction with Aryl bromide.

byproduct $\mathrm{CoS}$ and polysulphide ${ }^{16}$ via desulphurization/substitution/electrocyclization. ${ }^{17}$ On the other hand, oxidative addition of aryl iodide with cobalt complex can lead to the formation of $\boldsymbol{a}$ which can undergo intermolecular $C$ - $N$ cross-coupling reaction ${ }^{18}$ with unsubstituted tetrazoles using the base to give the intermediate $\boldsymbol{b}$ that can complete the catalytic cycle by reductive elimination to get target product arylamino tetrazoles. In addition, the atomic absorption of the aqueous solution active cobalt salt, $\mathrm{CoSO}_{4} \cdot \mathrm{H}_{2} \mathrm{O}$ was measured to reveal the presence trace of copper ${ }^{19 a}$ which was observed in the iron-catalyzed ${ }^{19 b}$ cross-coupling reactions as the active catalyst. However, in the present protocol, no trace of copper was detected with the detection limit of $1 \mathrm{ppm}$. This experiment clearly suggests that copper doesn't involve in the present methodology.

In addition, we have also tried the reaction with aryl bromide under optimized reaction conditions (Scheme 3). Unfortunately, the reaction could give target product in $19 \%$ yield only. However, no reaction could occur with aryl chloride under optimized reaction conditions.

\section{Conclusions}

In conclusion, we have developed a methodology for the regioselective synthesis of aryltetrazoleamines from thiourea in one pot multistep reaction. It is a general, efficient and easy method. Although the overall isolated yields look moderate, considering that the reactions are multi processes, the yields are in fact good to excellent. Many reports are available for the preparation of aminotetrazoles. However, the simplicity, environmental acceptability and cost-effectiveness of the cobalt make this method more practical. The reactions involved desulphurization followed by intermolecular $C$ - $N$ cross-coupling reaction.

\section{Supplementary Information (SI)}

Experimental data of all synthesized compounds and ${ }^{1} \mathrm{H} \&$ ${ }^{13} \mathrm{C}$ NMR scanned copies are available at www.ias.ac.in/ chemsci.

\section{Acknowledgements}

Authors thank Gitam University, Hyderabad for providing the laboratory facility for the experimental work. Authors also thank Dr. Ramana for truthful discussions during our experimental work.

\section{References}

1. (a) Ford R E, Knowles P, Lunt E, Marshall S M, Penrose A J, Ramsden C A, Summers A J H, Walker J L and Wright D E 1986 Synthesis and quantitative structure-activity relationships of antiallergic 2-hydroxy-N-(1H-tetrazol-5-yl)benzamides and $N$-(2hydroxyphenyl)- $1 H$-tetrazole-5-carboxamides $J$. Med. Chem. 29 538; (b) Peet N P, Baugh L E, Sundler S, Lewis J E, Matthews E H, Olberding E L and Shah D N 1986 3-(1 $H$-Tetrazol-5-yl)-4(3H)-quinazolinone sodium salt (MDL 427): a new antiallergic agent J. Med. Chem. 29 2403

2. Girijavallabhan V M, Pinto P A, Genguly A K and Versace R W 1988 Eur. Patent, EP274867 1989 Aromatic Hydroxyketones: Preparation \& Physical Properties Chem. Abstr. 11023890

3. (a) Akimoto H, Ootsuand K and Itoh F 1993 Eur. Patent EP530537, Green synthesis of the 1-substituted $1 H$ 1,2,3,4-tetrazoles by application of the Natrolite zeolite as a new and reusable heterogeneous catalyst Chem. Abstr. 119 226417; (b) Taveras A G, Mallams A K and Afonso A 1998 Int. patent W09811093 Tricyclic inhibitors of farnesyl protein transferase Chem. Abstr. 128230253

4. (a) Wittenberger S 1994 Recent developments in tetrazole chemistry, a review Org. Prep. Proced. Int. 26 499; (b) Herr R J and Biorg 2002 5-Substituted- $1 H$-tetrazoles as carboxylic acid isosteres: medicinal chemistry and synthetic methods Med. Chem. 10 3379; (c) Wistrandand LG and Frejd T 2003 Synthesis of fused tetrazoleand imidazole derivatives via iodocyclization Tetrahedron 59 6759; (d) Flippin L A 1991 Directed metalation and new synthetic transformations of 5-aryltetrazoles Tetrahedron Lett. 32 6857; (e) Rhonnstad P and Wensbo D 2002 On the relative strength of the $1 H$-tetrazol-5yl- and the 2-(triphenylmethyl)- $2 H$-tetrazol-5-yl-group in directed ortho-lithiation Tetrahedron Lett. 433137

5. (a) Jen K A, Holm A and Rachlin S 1966 Acta Chem. Scand. 20 2795; (b) Percival D and Herbst R M 1957 Alkylated 5-Aminotetrazoles, Their Preparation and Properties J. Org. Chem. 22 925; (c) Finnegan W G, Henry R A and Lieber E 1953 Preparation and isomerization of 5-alkylaminotetrazoles J. Org. Chem. 18779

6. (a) Moderhack D, Goos K H and Preu L 1990 Organic Reaction Mechanisms, An annual survey covering the literature Chem. Ber. 123 1575; (b) Gbrecht W L and Herbst R M 1953 The synthesis of certain 5aminotetrazole derivatives II. The action of hydrazoic acid on monoalkylcyanamides J. Org. Chem. 18 1014; (c) Herbst R, Roberts C W and Harvill E 1951 The synthesis of 5-aminotetrazole derivatives J. Org. Chem. 16 139; (d) Marchalin M, Martvon A and Collect C 1980 
Reactions of pyridyl isothiocyanates with diazoalkanes and azoimide Collect. Czech. Chem. Commun. 452329

7. (a) Klich M and Teutsch G 1986 Synthese de N-(tetrazol5-yl) azetidin-2-ones Tetrahedron 42 2677; (b) Barlin G B 1967 The relative electron-releasing power of a singly bound, and the electron-attracting power of a doubly bound nitrogen atom when present in the same fivemembered ring J. Chem. Soc. B 641

8. Ried W, Erle H and Liebigs E 1982 Science of Synthesis: Houben-Weyl Methods of Molecular Transformation Ann. Chem. 201

9. (a) Batey R A and Powell D A 2000 A General Synthetic Method for the Formation of Substituted 5Aminotetrazoles from Thioureas: A Strategy for Diversity Amplification Org. Lett. 2 3237; (b) Yu Y, Ostresh J M and Houghten R A 2004 Solid-phase synthesis of 5-aminotetrazole Tetrahedron Lett. 457787

10. Ramesh Y, Nilufa K, Saroj Kumar R and Bhisma K P 2011 Tandem regioselective synthesis of tetrazoles and related heterocycles using iodine Org. Biomol. Chem. 9 3235

11. (a) Demko Z P and Sharpless K B 2001 Preparation of 5-Substituted $1 H$-Tetrazoles from Nitriles in Water $J$. Org. Chem. 66 7945; (b) Demko Z P and Sharpless K B 2002 An Expedient Route to the Tetrazole Analogues $\alpha$-Amino Acids Org. Lett. 4 2525; (c) Himo F, Demko Z P, Noodleman L and Sharpless K B 2002 Mechanisms of Tetrazole Formation by Addition of Azide to Nitriles J. Am. Chem. Soc. 124 12210; (d) Himo F, Demko Z P, Noodleman L and Sharpless K B 2003 Why Is Tetrazole Formation by Addition of Azide to Organic Nitriles Catalyzed by Zinc(II) Salts? J. Am. Chem. Soc. 125 9983

12. (a) Lakshmikantam M, Shiva Kumar K B and Sridhar C 2005 Nanocrystalline ZnO as an Efficient Heterogeneous Catalyst for the Synthesis of 5-Substituted $1 H$-Tetrazoles Adv. Synt. Catal. 347 1212; (b) Lakshmikantam M, Balasubrahmanyam V and Shiva Kumar K B 2006 Zinc Hydroxyapatite-Catalyzed Efficient Synthesis of 5-Substituted $1 H$-Tetrazoles Synth. Commun. 36 1809; (c) Lakshmi Kantam M, Shiva Kumar K B and Phani Raja K 2006 An efficient synthesis of 5-substituted $1 \mathrm{H}$-tetrazoles using $\mathrm{Zn} / \mathrm{Al}$ hydrotalcite catalyst $\mathrm{J}$. Mol. Catal. A: Chem. 247186

13. Amantini D, Beleggia R, Fringuelli F, Pizzo F and Vaccoro L 2004 TBAF-Catalyzed Synthesis of 5-Substituted $1 \mathrm{H}$-Tetrazoles under Solventless Conditions J. Org. Chem. 692896

14. Tienan J, Fukuzou K, Shin $\mathrm{K}$ and Yoshinori $\mathrm{Y}$ 2008 Copper-catalyzed synthesis of 5-substituted $1 \mathrm{H}$ tetrazoles via the $[3+2]$ cycloaddition of nitriles and trimethylsilyl azide Tetrahedron Lett. 492824

15. Nasrollahzadeh M, Habibi D, Shahkarami Z and Bayat Y 2009 A general synthetic method for the formation of arylaminotetrazoles using natural natrolite zeolite as a new and reusable heterogeneous catalyst Tetrahedron 6510715

16. (a) Ramana $\mathrm{T}$ and Punniyamurthy $\mathrm{T} 2012$ preparation of 2-Azido-1-Substituted-1 $H$-Benzo[ $d]$ imidazoles Using a Copper-Promoted Three-Component Reaction and Their Further Conversion into 2-Amino and 2-Triazolyl Derivatives Chem. Eur. J. 18 13279; (b) Pinapati S,
Mandapati U and Rudraraju R R 2017 Iron-Mediated Desulphurization Towards the Synthesis of 2-Halo Aromatic Isothio cyanates Chemistry Select. 2 295; (c) Usharani M, Srinivasarao P and Rameshraju R 2017 Copper promoted desulfurization towards the synthesis of isothiocyanates Tetrahedron Lett. 58 125; (d) Mohan S, Bajavali S and Prasadrao K 2016 Cobalt Mediated by Desulphurization Towards the Synthesis of Isothiocyanates Synth. Comm. 461759

17. (a) Batey R A and Powell D A 2000 A General Synthetic Method for the Formation of Substituted 5Aminotetrazoles from Thioureas: A Strategy for Diversity Amplification Org. Lett. 2 3237; (b) Mohan S, Bajavali S, Ramana T and Prasadrao K 2016 An efficient methodology for the synthesis of thioureas from amine mediated by a cobalt source Tetrahedron Lett. 57 5297; (c) Mohan S, Bajavali S and Prasadrao K 2016 Cobalt Mediated by Desulphurization Towards the Synthesis of Isothiocyanates Synth. Comm. 46 1759; (d) Ali A R, Ghosh H and Patel B K 2010 A greener synthetic protocol for the preparation of carbodiimide Tetrahedron Lett. 51 1019; (e) Guin S, Rout S K, Gogoi A, Nandi S, Ghara K K and Patel B K 2012 Desulfurization Strategy in the Construction of Azoles Possessing Additional Nitrogen, Oxygen or Sulfur using a Copper(I) Catalyst Adv. Synth. Catal. 3542757

18. (a) Zhao D, Hu J, Wu N, Huang X, Qin X and Lan J You 2011 Regiospecific Synthesis of 1,2-Disubstituted (Hetero)aryl Fused Imidazoles with Tunable Fluorescent Emission Org. Lett. 13 6516; (b) Deng X, Mc Allister H and Mani N S 2009 CuI-Catalyzed Amination of Arylhalides with Guanidines or Amidines: A Facile Synthesis of 1-H-2-Substituted Benzimidazoles J. Org. Chem. 74 5742; (c) Lv X and Bao W 2009 Copper-Catalyzed Cascade Addition/Cyclization: An Efficient and Versatile Synthesis of $N$-Substituted 2-Heterobenzimidazoles $J$. Org. Chem. 74 5618; (d) Saha P, Ali M A, Ghosh P and Punniyamurthy T 2010 Cobalt-catalyzed intramolecular $C-N$ and $C-O$ cross-coupling reactions: synthesis of benzimidazoles and benzoxazoles Org. Biomol. Chem. 8 5692; (e) Cahiez G and Moyeux A 2010 CobaltCatalyzed Cross-Coupling Reactions Chem. Rev. 110 1435; (f) Tan B Y H and Teo Y O 2014 Efficient cobalt-catalyzed $C-N$ cross-coupling reaction between benzamide and aryl iodide in water Org. Biomol. Chem. 12 7478; (g) Amatore M and Gosmini C 2008 Synthesis of functionalized diarylmethanes via a cobalt-catalyzed cross-coupling of arylzinc species with benzyl chlorides Chem. Commun. 5019; (h) Li B, Wu Z H, Gu Y F, Sun C L, Wang B Q and Shi Z J 2011 Domino Condensation/S-Arylation/Heterocyclization Reactions: Copper-Catalyzed Three-Component Synthesis of 2$N$-Substituted Benzothiazoles Angew. Chem. Int. Edit. 123 1141; (i) Hammann J M, Haas D and Knochel P 2015 Cobalt-catalyzed negishi cross-coupling reactions of (hetero) arylzinc reagents with primary and secondary alkyl bromides and iodides Angew. Chem. Int. Edit. 54 447; (j) Zhao D, Hu J, Wu N, Huang X, Qin X, Lan J and You 2011 Regiospecific Synthesis of 1,2-Disubstituted (Hetero)aryl Fused Imidazoles with Tunable Fluorescent Emission J. Org. Lett. 13 6516; (k) Deng X, Mc Allister H and Mani N S J 2009 CuI-Catalyzed Amination of 
Arylhalides with Guanidines or Amidines: A Facile Synthesis of 1-H-2-Substituted Benzimidazoles J. Org. Chem. 74 5742; (1) Lv X and Bao W J 2009 Copper-Catalyzed Cascade Addition/Cyclization: An Efficient and Versatile Synthesis of $N$-Substituted 2Heterobenzimidazoles J. Org. Chem. 745618
19. (a) Larsso P F, Correa A, Carril M, Norrby P O and Bolm C 2009 Copper-catalyzed cross-couplings with part-permillion catalyst loadings Angew. Chem. Int. Edit. 48 5691; (b) Buchwald S L and Bolm C 2009 On the Role of Metal Contaminants in Catalyses with $\mathrm{FeCl}_{3}$ Angew. Chem. Int. Edit. 485586 